\title{
Sport psychology practice in Africa: Do culture-specific religion and spirituality matter?
}

\author{
Dr. John Elvis Hagan Jr. \\ Department of Health, Physical Education and Recreation, \\ University of Cape Coast, Private Mail Bag, Cape Coast- Ghana \\ "Neurocognition and Action - Biomechanics"- Research Group, \\ Faculty of Psychology and Sport Sciences/ Center of Excellence "Cognitive Interaction \\ Technology" CITEC, Bielefeld University, 33501 Bielefeld, Germany \\ Prof. Thomas Schack \\ "Neurocognition and Action - Biomechanics"- Research Group, \\ Faculty of Psychology and Sport Sciences/ Center of Excellence "Cognitive Interaction \\ Technology" CITEC, Bielefeld University, 33501 Bielefeld, Germany
}

Prof. Robert Schinke

School of Human Kinetics, Laurentian University, 935 Ramsey Lake Road, Sudbury, Ontario, P3E 2C6

\begin{abstract}
Religious and spiritual observances have been found in sport across parts of the world, notably in South and North America, Oceania and Sub-Saharan Africa. This is attributed to the indigenes' strong religious and /or spiritual belief in the sacred (God or Allah, a supreme deity, and/ or ancestors), who presumably, can turn the course of any life event in ones favour. To date, the potential connections between religion or spirituality and sport from research and applied consultancy perspectives remain uncharted. This conceptual submission reveals a distinction between religion and spirituality based on evidence from religious studies as well as how these could influence cognitivebehavioural practices in sport. These two phenomenological constructs have been shown to provide individuals with psychological resilience in the face of life adversities (e.g., coping) as well as offer other psychological support aimed at athletes' optimal functioning, performance enhancement and general well-being. To exemplify their manifestation, some peculiar and unique religious and spiritual practices reminiscent of a typical socio-cultural African context are highlighted. We suggest the use of new perspectives such as the athlete-centered and the RRICC models through different approaches (e.g., reflective practice) to facilitate their integration in sport. Future researchers should target the empirical and functional effects of these indigenous religious and spiritual practices through applied work on sport performance related constructs (e.g., flow and peak experiences, counseling interventions) in Sub-Saharan Africa.
\end{abstract}

Keywords: Spirituality, religion, culture, sport, psychology, Sub-Saharan Africa

\section{INTRODUCTION}

The intermingling of sport psychology and culture dates back to the early as 1990s, with the recognition that there is no universal approach to applied sport psychology with a seemingly lack of understanding among sport psychologists regarding how to work with athletes from diverse cultures unlike from their own (Schinke \& Moore, 2011). The notion of cultural diversity cannot be downplayed and offers a major challenge to sport and exercise psychology professionals. With increased globalization on interchange of people, objects, images, ideas, value systems, and information, contemporary sporting terrain has changed, showing some 
intriguing and challenging dimensions in the field (Ryba, Stambulova, Si, \& Schinke, 2013). According to Urry (2000), culture permeates via diverse mobilities, improves social relations, people's identities, and daily practices within and across many societies. For instance, crosscultural activities has brought many athletes, coaches, and sport psychology professionals from diverse cultural backgrounds in close contact with each other, and their individual life narratives may have invoked shared and varied memories as well as interpretations of their experiences (Ryba et al., 2013). Consequently, the goal of contemporary sport psychology practice from the International Society of Sport Psychology (ISSP) position stand is to build a more "inclusive" field that promotes research and practice that incorporate marginalized topics and cultural identities. This paradigm shift to culturally underpinned sport and exercise psychology gives recognition to unknown ethnocentric philosophical assumptions that currently prevails in theory, research, and practice (Ryba et al., 2013).

To date, scholarly information reveals that cross-cultural differences exist across a wide range of variables in sport (Schinke, Hanrahan, \& Catina, 2009). Researchers in sport psychology have identified cultural influences on processes as diverse as athlete identity (Hale, James, \& Stambulova, 1999; Schinke \& McGannon, 2015), attributions of success and failure (Hallahan, Lee, \& Herzog, 1997; Si, Rethorst, \& Willimczik, 1995), coping style Hoedaya \& Anshel, 2003; Ofori, Biddle, \& Lavallee, 2016), goal orientations (Isogai et al., 2003; Papaioannou, 2006), participation motives (Kolt et al., 1999), preferred coaching behaviors (Bolkiah \& Terry, 2001; Chelladurai et al., 1988), regulation of emotions (Mesquita \& Frijda, 1992), responses to athletic retirement (Stambulova, Stephan, \& Jäphag, 2007), and social physique anxiety (Isogai et al., 2001). Marginalized themes that are currently gaining prominence in contemporary sport or movement culture through studies, research, and applied practices are religion and spirituality (Jirásek, 2010; Parry, Watson, \& Nesti, 2011; Sarkar, Hill, \& Parker, 2015).

The current recognition of religion and spirituality has been "to ... catalyse a change in the focus of psychology from preoccupation only with repairing the worst things in life to also building positive qualities" (Seligman \& Csikszentmihalyi, 2000, p. 5). Within clinical and positive psychology, evidence suggests that religion and spirituality may protect individuals from the stressors they encounter by providing people with greater psychological resilience in the face of life adversities (Peres, Moreira-Almedia, Nasello, \& Koenig, 2007). These two phenomenological constructs may also provide a cognitive framework for more holistic understanding of the world through life rituals or routines. Although work in sport on how these constructs could help optimize sporting success and well-being is not extensive, few studies within the sport psychology literature have investigated the connection between religion, spirituality, and well-being in sport performers (Sarkar et al., 2015). For example, Storch, Storch, Kovacs, Okun, and Welsh (2003) noted that intercollegiate athletes' internal commitment to personal religious and spiritual beliefs was inversely related to substance use. Due to the correlational nature of this study, the authors only inferred that some athletes were more likely to use their religious and spiritual beliefs to manage with their stressors (e.g., injury and academic hardship). Others studies have empirically found support that religious and/ or spiritual beliefs are significant contributors toward athletes' sporting careers across different populations on various themes. These beliefs have been found to help athletes react positively to their personal problems and offer a deep meaning to their successes and failures in sport (Sarkar et al., 2015; Vernacchia, McGuire, Reardon, \& Templin, 2000). Likewise, prayer as a religious and/ or spiritual practice has also been noted as a coping mechanism and performance enhancement technique for many athletes (Czech \& Bullet, 2007; Maranise, 2013). Given that religion and spirituality have been identified to improve the welfare of numerous individuals in different psychology domains, the minimal exploration could be 
attributed to the phenomenological and multifaceted nature of religion and spirituality that is not well understood by many as well as the lack of perhaps standardized objective measuring instruments for these constructs. Schinke, Stambulova, Si, and Moore (2017) highlighted the importance of integrating new perspectives in athletes' environments in order not to prevent performers from expressing their uniqueness that may cause identity crisis. Even more noticeable in the recent growth of awareness in this area of cross-cultural literature, is the dearth of information regarding the role of religion and spirituality in the life of athletes from diverse populations despite their strong association with traditional religious and spiritual practices (Sarkar et al., 2015).

\section{PURPOSE AND JUSTIFICATION}

From a cross-cultural perspective, our authors aim is to reveal the uniqueness of religion and spirituality in a typical socio-African context because these constructs form the core beliefs and values that shape the identity of many indigenes of the region. The Sub-Saharan region represents a heterogeneous sample of different ethnic identities with varied religious and spiritual practices. Our authors seek to clarify the conceptual difference between religion and spirituality and their connection from an African perspective. We also show the interplay between religion, spirituality, sport, and research. Consideration is further given to how some indigenous religious and spiritual observances could potentially influence the future of sport psychology consultancy in Sub-Saharan and other indigenous societies across other parts of the world. Additionally, issues relating to transnationalism and athletes, coaches and sport psychology consultants' mobility require a deeper and shared understanding of diverse psychological phenomena related to transnational mobility in sport, and joint efforts in developing culturally competent athletic migration research and practice, extending also to mobile practice (Ryba et al., 2017). A dialog on how potential frameworks or approaches regarding future research and applied work could be enhanced is also outlined. The fact is that religion and spirituality form part of contextualized cultural reflections that could potentially be harnessed to offer psychological support aimed at athletes' optimal functioning, performance enhancement and general well-being. These cultural reflections are believed to promote sport psychology and other sport science related practices through multicultural awareness of training methodology and other improvements in staff competence (Sarkar et al., 2015; Schinke, Hanrahan, \& Catina, 2009).

Additionally, the notion and significance of cultural praxis which is an emerging area under cultural sport psychology (CSP) is yet to be well embraced by researchers and applied professionals in sport. This new area focuses on broadening the epistemological spectrum of theory and practice in CSP that challenges decontextualized knowledge to a new way of thinking about athletes as constituted by varied discourses and identities (Ryba \& Wright, 2005, 2010).

Due to the absence of systematic research on religiousness of athletes, applied work has inferred religion and /or spirituality as a core value within the lives of many elite athletes (Storch, Kolsky, Silvestri, \& Storch, 2001). Some religious and spiritual related issues have been identified in applied sport psychology to interact with sport performance (Balague, 1999; Hoffman, 1992). Matters such as athletes' challenges of understanding their physical gifts, the tangible gains they receive, and the idealizations of their talents have been acknowledged. The quest for athletes' self-worth and general life meaning has led to the integration of religious or spiritual related issues for guidance in sport (e.g., consulting oracles and priests before, during, and after competitions, Pannenborg, 2012; Storch et al., 2001). Likewise, many athletes turn to religion and spirituality for hope and security. For instance, distressing situations such as losing a final event and injury could enable athletes to pray for divine intervention or inner 
strength to cope with these challenges in order to optimize their psychological state towards improved performance (Hoffman, 1992). Religiosity and spirituality may serve as a cognitivebehavioral tools that could help athletes persevere through hardships they encounter. According to Higdon (1992), athletes may benefit from religious cognitions such as empathy and comfort through social support and internal strength critical for enduring stressful situations. Therefore, it is not surprising to notice Catholic religious observances in Brazilian football and perhaps other sports for counseling and competition related interventions. For example, the Brazilian Olympic Committee was reported to have hired a priest to work with the national teams (athletes, coaches, and management) during the Athens Olympic Games (Moraes \& Salmela, 2009). Similar trends exist in Sub-Saharan Africa of the hiring of spiritually acclaimed persons for all manner of performance and career related consultations (Hagan \& Schack, 2017; Pannenborg, 2012).

\section{CONCEPTS OF RELIGION, SPIRITUALITY, AND THEIR BENEFITS}

The two terms, religion and spirituality, have often been used interchangeably (e.g., Egli, 2013; Jirásek, 2015). Although both constructs are closely related, they need to be operationalized and clarified. Argyle and Beit-Hallahmi (1975) defined religion as "a system of beliefs in divine or superhuman power, and practices of worship or other rituals directed toward such a power" (p. 1). Generally, attention is paid to a doctrine that outlines the values and beliefs of the faith, and spiritual models to emulate. According to Hill et al. (2000), religion may also include a search for non-sacred goals (e.g., identity, belongingness, or wellness) with the sacred search process receiving validation and support from an identifiable group of people. Major religious affiliations of the world include Christianity, Judaism, Buddhism, Hinduism, Islam, and African Traditional religion among others, with various branches often varying on a liberal to conservative continuum (de Witte, 2008; Plante, 2008). Sport provides a unique and imaginable platform for sensual manifestation of power through cognitive-behavioral awareness that religion provides (e.g., the performance of religious rituals; prayer, wearing Christ-like necklaces, worship, and other spiritual objects). Rather than referring to an abstract system of beliefs, symbols and distant spirit beings, sport offers people the contextual recognition of the immediate presence of sensory facilitation beyond control and understanding that can affect one's daily life for the good or bad. Therefore, daily practices of connecting to and disconnecting from the sacred may cross the self-defined boundaries between 'religions'. From this premise, religion through sport may require a practice of mediating the imagination and experience of supernatural presence to optimize one's experiences through meta-cognition and other cognitive and emotional processes. These psychological processes could help athletes with how to approach a given motor task. Athletes can monitor and carefully evaluate their progress toward a successful completion through the refinement of their cognitive-perceptual motor skills in a close interaction with environmental conditions and factors as described in action theory approach to applied sport psychology (see Schack \& Hackfort, 2007). Additionally, religion and spirituality may potentially help individuals to overcome personal conflicts in their daily life and subsequently initiate future plans (Schack \& Schack, 2017).

Spirituality on the other hand originates from "spirit", coined from a Latin word "spiritus", meaning breath, air, and life principle; therefore, "spirituality is about the practice and outworking of the spirit and the ways which it is developed, with its different aspects and relationships connected, sustained and understood" (Robinson, 2007a, p. 24). Robinson (2007a) emphasized three areas required to develop a working definition: (1) awareness and appreciation of the other; (2) the capacity to respond to the other; and (3) developing life meaning. Awareness and appreciation of the other comprise the self, interpersonal 
relationships, groups, the environment, and a deity, showing that spirituality is relational. Responding to the connection between self, interpersonal relationships and a sacred being illustrates the action one takes in the light of one's own belief to spirituality. Developing understanding reveals how one finds meaning and value that includes one's hopes, purposes, and resolutions that are often found through experience. Sport psychology then offers a foundation of developing a sense of purpose, value, and commitment that athletes might not necessarily be conscious of. Belief or efficacy or faith from a spiritual lens becomes a significant indicator for achieving performance excellence in sport (Fowler, 1981). Regarding performance excellence, Ravizza (2002) suggested "when physical, mental, and emotional components join together, movement takes on a spiritual dimension in the sense of purpose that is attained" (p. 14). Spirituality becomes a holistic construct that typifies "an athlete's close relationships, or extraordinary and self-affirming moments in life such as winning an Olympic medal, or securing a personal best" (Watson \& Nesti, 2005, p. 229). Hence, religion and/ or spirituality may intersect with sport to bring life's purpose and meaning to athletes, coaches, and other personnel through applied practice in an attempt to attain performance excellence.

Applied work in sport can tap into the psychological and physical benefits of religion and spirituality such as good health and well-being (Koening, McCullough, \& Larson, 2001; Plante \& Thoresen 2007). Athletes who actively engage in religious and spiritual practices are likely to be healthier, have better habits, and receive more social support than those who do not (Czech \& Bullet, 2007; Maranise, 2013, \& Storch et al., 2003). According to Plante (2008), an individual's religious and spiritual involvement is associated with positive health behaviours such as less smoking and drinking alcohol, unsafe sexual activity, and more exercise and healthy eating. Inversely, the new ISSP position on mental health reveals that substance issues, without spirituality in athletes' life, may erode their mental health (Schinke et al., 2017). Therefore, athletes stand a better chance of minimizing the high risk of engaging in some of these health-compromising behaviours (Watson \& Nesti, 2005; Ravizza, 2002). Likewise, they may cope better with the stressors in their lives (e.g., competition, family, drugs, career termination) and have better mental health functioning such as more optimism, compassion for self and others, forgiveness, and less symptoms of anxiety and depression, especially at the elite level (Czech \& Bullet, 2007; Storch et al., 2003).

Therefore, it is imperative that the sport fraternity does not overlook the interface between religion, spirituality and sport. This relationship has grown overtime with acceptance of sport as a physical, psychological, moral, and emotional entity that does not exist in a social vacuum but rather, it has advanced and progressed in accordance with a multiplicity of cultural and historical practices and at the same time embedded itself into the everyday life of many people including athletes and officials from diverse religious and spiritual backgrounds (Parker \& Watson, 2014). Hence, the relationship between religion, spirituality and contemporary sport is a reflection of the extent to which sport has increasingly impacted wider society and has progressed from being a marginal past-time to an established feature of popular culture with many unaccustomed dimensions.

\section{RELIGION, SPIRITUALITY, AND SPORT PSYCHOLOGY}

Within the religion-spirituality-sport literature, some researchers examined a range of issues including prayer and ritual (Hoffman, 2011; Jirásek, 2015, 2010), idolatry (Watson and White, 2012), and identity (Watson, 2011). However, it was Watson and Nesti (2005) earlier work that addressed the specific role of religion and spirituality in sport psychology consulting in four major areas: incorporating religion and spirituality into current athlete-centered models; integrating religion and spirituality into mental skills training; drawing the association 
between religion, spirituality, and positive psychological states, such as flow and peak experiences; and utilizing religion and spirituality in sport psychology counseling. Attempting to address some of the issues raised by Watson and Nesti (2005), Gamble, Hill, and Parker (2013) investigated the role and influence of sport psychologists and sport chaplains with a sample of English Premiership soccer clubs. Gamble and associates found that sport psychologists primarily focused on performance enhancement while chaplains offered other psychological needs (e.g., career related counseling). Multi-faith spiritual guidance through the use of chaplains is now common in United States university sport programs and national football league (NFL). To achieve greater impact within this context, Gamble et al. suggested that future research is warranted to explore the potential of a collaborative partnership between the sport psychologist and other personnel (e.g., chaplain), and how they could work more effectively with significant others (i.e., coaches and managers) to provide support to their athletes through intervention related studies among cohorts in different sport disciplines. Due to the high indulgence of religious and spiritual practices in some parts of the globe, it would be interesting to understand how these native practices do optimize sport performance through specific contextual issues to promote research and applied work. Ravizza (2002) reiterated the need for the physical, mental, emotional, and spiritual dimensions of athletes' performance and life not to be underestimated, calling for a more holistic and balanced research and consultancy approach to specific techniques and a broader epistemological perspective for performance enhancement. Hence, establishing a framework that integrates issues about religion and spirituality may provide athletes, coaches and sport psychology consultants of different cultural background and ethnic identity a valuable source for addressing both sport and non-sport related issues (Ryba et al., 2017; Watson \& Nesti, 2005).

\section{Context Setting}

Cultural values displayed in many parts of Africa are by no means unique to the continent and general life in most African settings is different from life in other parts of the world (e.g., Dzokoto, 2010). These values could be seen from the customary beliefs, social norms, and unique traits of different ethnic, religious, and social groups (Schinke et al., 2009). Religious and/ or spiritual orientation and finding time for related behaviours are pervasive and structure the lives of nationals from the sub-region (Hagan \& Schack, 2017; Ikulayo \& Semidara, 2011).

Based on the aforementioned assertions, two modes of causalities (i.e., the scientific and spiritual causations) have been ascribed to life occurrences of the indigenes from the Subregion. These two modes cohabit, coexist and are not mutually exclusive (Schatzberg, 2006). According to Schatzberg (2006), the two modes may rival the dominance of each other towards the causal understanding in the lives of the people in some cultural contexts and at different times. Most ordinary people alternate these causalities as the need arises and depending on the situation and specific context, one may come to the fore rather than the other. Obviously, the spiritual or supernatural mode of causal understanding does not align with the causal underpinning of most empirical social sciences. Nonetheless, the local people believe in its operations and actively explore its usage to understand their life influences (Ashforth 2005; Fauconnier \& Turner, 2002). This mode of causality will be used throughout the review to elucidate how sport psychology professionals could tap into these localized practices to improve consultation and research.

Many people from the Sub-Saharan region understand religiousness and / or spirituality as a mode of causality because they believe that the forces of the day and night, as well as those possessing the ability to harness them, often influence an individual's life chances and daily events, including sport (Hagan \& Schack, 2017; Pannenborg, 2012; Schatzberg, 2006). As a 
means of accomplishing certain results in the physical world by vigorously triggering the intervention of the supernatural world, Ashforth $(2000,2005)$ reiterated that religion and spirituality are contemporary phenomena that individuals may use to handle insecurity and uncertainty in sport. These local beliefs mean that when working as an applied sport psychology consultant in Sub-Saharan countries, it is noteworthy to appreciate the significance of indigenous customary beliefs, values, and localized practices because they are believed to offer supernatural interventions to any life event. These spiritual practices (e.g., worship, praise, dance, incantation, psyching verses) may offer other intervention related options (e.g., problem-solving skills) to athletes in times of crisis (de Witte, 2008; Ikulayo \& Semidara, 2009).

The overwhelming acceptance of religious and spiritual practices in the Sub-Saharan Africa influence many athletes to profess faith as a source of inspiration before and during competitions. This undoubtedly has a huge implication for applied work in this region and other athletes who are transnational (Diehl, Hegley, \& Lane, 2009; Ikulayo \& Semidara, 2009; Ryba et al., 2017). The current nascent stage of sport psychology development and recognition in the sub-region inhibits applied work on the differential impact of psychological variables such as religion and spirituality to promote athletes' behaviours, mental processes, and wellbeing may be due to an area that is not well understood, hence its marginalization. Attention on advocacy through research and other educational training to offer a deeper understanding of psychological variables that may potentially impact on sport performance and general wellbeing of athletes is required.

\section{Religious And Spiritual Observances In And Through Sport}

The linkages between religiosity and spirituality date back to the Ancient Greeks where sport was considered as a setting aimed for the development and exhibition of virtue (excellence) that improved the person and society (Schinke et al., 2015). So an Olympic festival in those days was seen as an exercise of devotion to Zeus, the Greek god, with time split between traditions, religious ceremonies and competition. Other Greek athletic festivals were held to pay homage to different gods, promote peace, friendship, unity, and for entertainment purposes (Reid, 2009; Roberts \& Yamane, 2012). Evidence exist of similar events in parts of Sub-Saharan countries (e.g., Ghana, Nigeria, Cameroon), where commemorative sport events are organized to herald the climax of traditional and other religious festivals (Pannenborg, 2008). Today, the battle of supremacy through rivalries in world sport has tilted the dynamics of engaging in spiritual related issues for merely honour and entertainment (Baker, 1988; Tyler \& Cobbs, 2015). The upsurge of issues about religion and spirituality in Africa is deeply rooted in long standing traditions, identities and healing ceremonies (Pannenborg, 2012; Schack \& Schack, 2017). Noticeable pre-event practices in most official social gatherings including sport events are the use of prayers, drumming, dancing, and other traditional rituals (Hagan \& Schack, 2017; Ikulayo \& Semidara, 2009). Other contextual examples can be seen in New Zealand, where All Blacks (national rugby team) and some native boxers observe the "Maori" dance before competitive assignments. We believe all these culture-specific behaviours might have influenced recent attention to the notion of cultural competence in sport psychology, that is the challenge of delivering evidence-based interventions that maintain respect for and consideration of cultural characteristics such as indigenous practices including religion and spirituality (Ryba et al., 2013; Schinke \& Moore, 2011). So what are some of the religious practices commonly associated with sport in parts of Sub-Saharan Africa? The answers are captured in the next paragraphs. However, unless otherwise stated, most cited examples are from football because literature on other sports, to our knowledge, is undocumented, 
though likely exist because football enjoys overwhelming dominance in terms of media reportage, patronage and financial investments over and above other sports.

Many football teams in Sub- Saharan Africa mirror and shape their emerging identities from towns and cities, where ethnic and religious loyalties among other factors coexist (Pannenborg, 2012). Community-based clubs from most Sub-Saharan states adopt names based on traditional and/or religious symbols. For example, Ghana's Asante Kotoko football club derives its identity from the origins of the great Ashanti kingdom. Similar examples are found with Kaizer Chiefs (Johannesburg, South Africa), ASEC Mimosa (Abidjan, Ivory Coast), Canon (Yaoundé, Cameroon), Simba (Dar es Salaam, Tanzania), Gor Mahia (Nairobi, Kenya) among others. Located in Northern Ghana, Real Tamale United (RTU) is primarily a Muslim club, drawing its support based on territory and religion. Two glamorous football club names in Ghana are found in the city of Cape Coast (the capital of Central Region). Drawing their support base from the Fante ethnic group, this city's most popular teams are Venomous Vipers and Mysterious Ebusua Dwarfs. The latter's name is derived from an Akan belief in forestdwelling spirits, commonly known as dwarfs. From Cameroon, one of the most prominent clubs, Canon Yaoundé, derives its name from a purported famous gun that was brought by the Germans who were defeated in 1916. This gun when shot exhibited rattled sounds "Kpa Kum", reminiscent of warfare in the colonial era. Such names can also be observed elsewhere (e.g., Nigeria, Benin, and Togo; Pannenborg, 2012). Africa's national teams are also not excluded from such names. A few listed names include Togo (Sparrow Hawks), Senegal (Teranga Lions), Ivory Coast (Elephants), Cameroon (Indomitable Lions), and Nigeria (Super Eagles formerly Green Eagles). These teams are believed to assume animalistic attributes such as strength, endurance, speed, bravery, and resilience, with the belief of mimicking these attributes during competitive fixtures for performance enhancement.

The connections between football, religious and spiritual matters are closely associated with indigenous traditions and beliefs in the sacred (a supreme deity, ancestors and/ or God) in Sub-Sahara. Even though players, coaches and other analogous personnel may have their own beliefs, they are often initiated into club traditions during their time at the clubs (Pannenborg, 2008, 2012). Traditional rulers, chiefs, and priests from other faiths are visited for spiritual assistance that are purported to turn the fortunes of the clubs before and during major competitions through sacrifices. These sacrifices are also made to establish a great bond between the clubs, their territories and fan base, suggesting a perceived supremacy over the other clubs.

Religious and spiritual practices are performed on the field of play by players, officials, and spiritual advisers. More noticeable from the electronic and print media footage are the pouring of libation with local drinks, sprinkling of food and other objects on pitches to perceived ancestors of the land for divine intervention. Players are often seen praying for spiritual assistance before matches for their own or their team's success. These athletes make the sign of the cross, raise their fingers toward heavens, go on their knees, and so on (Hagan \& Schack, 2017, Jirásek, 2015; Pannenborg, 2008, 2012). The most common items seen with players of both Christian (especially Catholics) and Muslim faith during their prayer time are the citing and wearing of the rosary and the use of amulets or talismans by players with traditional orientations. Such identifiable behaviours can also be found in Brazilian sport. Many athletes use traditional religious superstitions and practices in their sport. For example, some wear necklaces with Christ on the cross for personal protection against azarão, or bad luck. Others prefer African voodoo rituals, called mandinga and macumba, during ritual practices called candonblé, santeria and ubanda. These indigenous behaviours are common among Brazilian 
athletes of African descent, especially in football (Moraes \& Salmela, 2009, p. 119). Coaches and other personnel from diverse cultural backgrounds (e.g., Ghana, Nigeria, Cameroon, Brazil) have also integrated religious and superstitious behaviours into their work. For example, coaches have been known to wear the same uniforms, shirts, or other apparel during a whole sporting season to give them luck against their opponents (Diehl et al., 2009; Mooraes \& Salmela, 2009; Pannenborg, 2012). They sometimes use amulets or rituals to help them during competitions. Even though these practices may seem superstitious, they might bear some religious and spiritual connotation. According to Jirásek (2015), these acts may appear to be superficial examples of how religious and spiritual practices permeate sporting events. Suffice to say that religion and spirituality related issues may play critical roles in shaping institutional values across diverse cultural backgrounds through sport.

Beliefs in Christianity and Islam go alongside Traditional African beliefs (witchcraft, sorcery, magic and other spiritual powers) in many parts of Sub-Saharan Africa (de Witte, 2008, Pannenborg, 2008). The dualistic thinking surrounding the sacred makes players switch allegiance in search of quick breakthroughs or interventions. This is because the intermediaries of religious and spiritual matters are believed to have equal standings in these societies based on their spiritual powers regardless of their affiliation (Pannenborg, 2008). Therefore, the linkage between religion and spirituality cannot be ignored regarding both research and sport psychology consultancy in the sub-Saharan region. Moraes and Salmela (2009) affirmed that sport psychology consultants need to think twice when working with athletes or coaches to ensure that their interventions do not contradict or disparage religious influences from societies that are deeply-rooted in diverse customary beliefs and values. Many athletes convey their multifaceted and social identities and other uniqueness into training and competition, requiring better understanding from scholars and practitioners working with these athletes from disparate religious and/ or spiritual denominations (Schinke et al., 2017). These religion and spiritual matters form the core of the Sub-Saharan society, as such many athletes attribute the successes or otherwise of their performance if God or Allah or any sacred being willed it (Schinke, 2005). To date, some coaches and few established sport psychologists in the sub-region have dovetailed some of these localized religious practices as part of their pre, during and post-performance routines to accommodate the religious and spiritual beliefs of both athletes and officials in an attempt to seek for supernatural interventions toward performance enhancement and other career related challenges (e.g., during injuries [de Witte, 2008; Ikulayo \& Semidara, 2011]).

\section{FUTURE DIRECTIONS}

The preceding literature clearly shows that some religious and spiritual observances such as prayer can be helpful, especially for athletes who hold strong religious convictions. These behaviors appear to provide pre-competition awareness training and alleviate performancerelated anxieties. They also permit the centralization of parts of athletes' identities in the sport context, supporting the whole person. These findings largely substantiate the ancient teachings of all the monotheistic religions. Jewish, Christian, Muslim and recently, African Traditional, Shamanism believers have used prayer and traditional healing ceremonies as means of strength and comfort in times of trouble and adversity (de Witte, 2008; Schack \& Schack, 2017; Watson \& Nesti, 2005).

Research to date in sport psychology has only examined prayer experiences of Christian athletes in sport. According Watson and Nesti (2005), it is plausible that athletes from different religious traditions such as that from Sub-Saharan Africa may employ different types of religious practices typical of specific cultural antecedents in their sporting life. Athletes from Christianity and Islam backgrounds are most likely to direct their prayer to God. Performers from African Traditional, Buddhism or Hinduism orientations may adopt meditative 
techniques to relax the mind and attain focus from the onset of competition through applications such as autogenic training. Further research in sport psychology could explore the diversity of indigenous religious and spiritual observances such as prayers, libations, psyching verses, and incantations used by athletes of African descent through intervention related empirical investigations.

New approaches that have been proposed to aid better understanding include reconciling religiosity and spirituality into athlete-centered models that seek to optimize personal and performance excellence of athletes. Personal and performance excellence relate to a wide range of life skills that may contribute to holistic health and well-being across the life span as well as quantifiable outcomes from competitive sport. Current life skills models include moral, social, psychological, emotional, and intellectual aspects of an athlete's life. Religiosity and spirituality have been suggested under the umbrella of life skills in sport that are thought to provide a holistic service (promoting health and personal growth) in sport psychology (Jirásek, 2015; Miller \& Kerr, 2002) despite the lack of training among professionals regarding how to integrate its practical utility as part of one's work.

The integration of religion and spirituality as part of mental skills training (MST) and preperformance routines (PPR) can be more relevant for mental preparation of athletes before sport events (Hagan \& Schack, 2017; Miller \& Kerr, 2002). The usefulness of religious and spiritual observances such as prayer, psyching verses and verbalizations means that these behaviours could be incorporated as part of MST and PPRs. These approaches serve as regulative cognitive-behavioural strategies not only to enhance sport performance, but may also improve the quality of sport experience, increase psychological skills, facilitate athletes' well-being and personal development (Anderson, Miles, Mahoney, \& Robinson, 2002; Schack, Witmarsh, Pike, \& Redden, 2005; Velentzas, Heinen, Tenenbaum, \& Schack, 2010). For researchers and applied consultants to recognize religion and/ or spirituality as beneficial adjunct to conventional psychological skills and routines programmes, we need to accelerate a deeper understanding by incorporating these constructs into educational models in cultural sport psychology (CSP) and other sport programmes.

The principles of respect, responsibility, integrity, competence, and concern for others model (RRICC; Plante, 2007) also provide ethical guidelines for psychologists and mental health professionals involved with religion, spirituality, and psychotherapy integration. Primarily, the RRICC model emphasizes the importance of the aforementioned professionals to: respect the beliefs and values associated with religion and spirituality; have a responsibility to be aware and thoughtful of how religion and spirituality impacts others; act with integrity in terms of being honest about their skills as professionals; provide competent professional services by integrating religion and spirituality into their professional psychology work; and show concern for the well-being and welfare of others. Plante identified and discussed four ethical dilemmas associated with issues of respect (religious and spiritual bias), integrity (blurred boundaries and dual relationships), competence (assuming expertise in a faith tradition), and concern (destructive religious beliefs and behaviours; cf., Sarkar et al., 2015). This model is expected to help sport psychologists and other professionals better direct the often challenging terrain of religious and spiritual matters in sport.

The complexity of these interrelated constructs in a typical socio-cultural context has led to the development of four key signposts for enhancing indigenous psychology work from western perspectives (Yang, 1997). These signposts are as follows:

1. giving priority to the study of culturally unique psychological and behavioural 
phenomena or characteristics of the local people;

2. investigating both the specific content and the involved process of the phenomenon;

3. beginning any research with a thorough immersion into the natural, concrete details of the phenomenon to be studied; and

4. basing research on local intellectual traditions rather than western intellectual traditions.

\section{CONCLUSIONS}

We believe that knowing the connection between religion and spirituality in the life of athletes from indigenous societies like Sub-Saharan nations that over the years have produced top level athletes in various disciplines can foster deeper and stronger athlete-coach/psychologist cooperation. Any applied intervention that fails to recognize the typical socio-cultural context and indigenous identities of the athletes would be an exercise in futility. The truth is that sport psychology consultants would work with athletes with dual or multiple religious and spiritual beliefs including unaccustomed African traditional values. Therefore, it is imperative that the notion of cultural praxis which focuses on a deeper understanding (knowledge) of culturally constituted beliefs and values and cultural skills (cultural reflexivity) are brought to the fore in applied work (Ryba \& Wright, 2005, 2010). The RRICC model, for example, also provides a useful framework for practitioners (researchers, coaches, psychologists) who are interested in issues about religiosity and spirituality. The bases for such works have been echoed by local scholars (Adams, 2005; Dzokoto, 2010), who have advocated for more Sub-Saharan psychological research and cross-cultural approaches. These developments fit perfectly in recent advances for more culturally underpinned sport psychology, driven by other scholars from the western world and ISSP position (e.g., Ryba et al., 2013; Schinke et al., 2009). The fact that local cultures, histories, and social organizations on the concepts, methods, analysis, and interpretation of these constructs could impact on both research and applied work call for further empirical scrutiny. This scrutiny may provide potential possibilities for reconnecting nature with some orthodox psychological strategies such as imagery, concentration, relaxation, and selftalk. Hence, developing sport psychological practice through a cultural lens with new scientific advancements could deepen sport psychologist-coach-athlete interactions toward athletes' well-being and perhaps performance enhancement. Additionally, with the ever increasing phenomena of transnational athletes and coaches mobility across the globe, researchers and consultants need to understand this area, not only for the sake of athletes, but also to foster effective cultural inclusiveness and integration within teams and sport organizations.

\section{References}

Adams, G. (2005). The cultural grounding of personal relationship: Enemyship in North American and West African worlds. Journal of Personality and Social Psychology, 88, 948-968.

Ashforth, A. (2000). Madumo: a man bewitched. Chicago: University of Chicago Press.

Ashforth, A. (2005). Witchcraft, violence, and democracy in South Africa. Chicago: University Of Chicago Press.

Anderson, A.G., Miles, A., Mahoney, C., \& Robinson, P. (2002). Evaluating the effectiveness of applied sport psychology practice: Making the case for a case study approach. The Sport Psychologist, 16, 432-453.

Argyle, M., \& Beit-Hallahmi, B. (1975). The social psychology of religion. London: Routledge \& Kegan Paul.

Baker, W. J. (1988). Sport in the Western world (revised ed.). Urbana: University of Illinois Press.

Balagué, G. (1999). Understanding identity, value, and meaning when working with elite athletes. The Sport Psychologist, 13, 89-98.

Bolkiah, S., \& Terry, P. C. (2001). Coaching preferences of athletes in Brunei Darussalam and Great Britain: A cross-cultural test of the path-goal theory. In Papaioannou, A., Goudas, M., \& Theodorakis, Y. (Eds.), Proceedings of the International Society of Sport Psychology 10th World Congress (pp. 8-10). Thessaloniki, Greece: Christodoulidi Publications. 
Chelladurai, P., Inamura, H., Yamaguchi, Y., Oinuma, Y., \& Miyauchi, T. (1988). Sport leadership in a cross-national setting: The case of Japanese and Canadian university athletes. Journal of Sport \& Exercise Psychology, 10, 374-389.

Czech, D. R., \& Bullet, E. (2007). An exploratory description of Christian athletes' perceptions of prayer in sport: A mixed methodological pilot study. International Journal of Sports Science \& Coaching, 2(1), 49-56.

de Witte, M. (2008). Spirit media: charismatics, traditionalists, and mediation practices in Ghana. PhD Thesis, Institute for Social Science Research (AISSR), University of Amsterdam, Amsterdam.

Diehl, C. D. P., Hegley, A., \& Lane, A. M. (2009). Working with Ghanaian athletes. Cultural sport psychology. Champaign, IL: Human Kinetics.

Dzokoto, V. (2010). Different ways of feeling: Emotion and somatic awareness in Ghanaians and Euro-Americans. Journal of Social, Evolutionary, and Cultural Psychology, 4(2), 68.

Egli, T. J. (2013). AASP-certified consultants' experiences of spirituality within sport psychology consultation. The Sport Psychologist, 28(4), 394-405.

Fauconnier, G. \& Turner, M. (2002). The way we think: conceptual blending and the mind's hidden complexities. New York: Basic Books.

Fowler, J. W. (1981). Stages of faith: The psychology of human development and the quest for meaning. San Francisco, CA: Harper \& Row Publishers.

Gamble, R., Hill, D. M., \& Parker, A. (2013). Revs and psychos: Role, impact and interaction of sport chaplains and sport psychologists within English premiership soccer. Journal of Applied Sport Psychology, 25(2), 249-264.

Gill, D. P., \& Kamphoff, C. S. (2010). Sport psychology and representation. In T. V. Ryba, R. J. Schinke, \& G. Tenenbaum (Eds.), Cultural turn in sport psychology (pp. 53-74). Morgantown, WV: Fitness Information Technology.

Hagan, J. E., \& Schack, T. (2017). Integrating pre-game rituals and pre-performance routines in a culture-specific context: Implications for sport psychology consultancy. International Journal of Sport and Exercise Psychology, 15(1), 1-14. doi:10.1080/1612197X.2017.1292301

Hale, B. D., James, B., \& Stambulova, N. (1999). Determining the dimensionality of athletic identity: A 'Herculean' cross-cultural undertaking. International Journal of Sport Psychology, 30, 83-100.

Hallahan, M., Lee, F., \& Herzog, T. (1997). It's not just whether you win or lose, it's also where you play the game: A naturalistic, cross-cultural examination of the positivity bias. Journal of Cross-Cultural Psychology, 28, 768-778.

Higdon, H. (1992). Is running a religious experience? In S.J. Hoffman (Eds.), Sport and religion (pp. 77-81). Champaign. IL: Human Kinetics.

Hill, P. C., Pargament, K. I., Hood, R. W., Jr., McCullough, M. E., Swyers, J. P., Larson, D. B. et al. (2000). Conceptualizing religion and spirituality: Points of commonality, points of departure. Journal for the Theory of Social Behavior, 30, 51-77.

Hoedaya, D., \& Anshel, M. H. (2003). Coping with stress in sport among Australian and Indonesian athletes. Australian Journal of Psychology, 55, 159-165.

Hoffman, S. J. (2011). Prayer out of bounds. In J, Parry. M. S. Nesti \& N. J. Watson (Eds.) Theology, ethics and transcendence in sports (pp.35-63), London: Routledge.

Hoffman, S. J. (1992). Religion in sport. In S. J. Hoffman (Ed.), Sport and religion (pp. 127-141). Champaign, IL: Human Kinetics.

Howe, P. D., \& Parker, A. (2014). Disability as a path to spiritual enlightenment: An ethnographic account of the significance of religion in paralympic sport. Journal of Disability \& Religion, 18(1), 8-23. http://dx.doi.org/10.1080/15228967.2014.868988

Ikulayo, P. B., \& Semidara, J. A. (2011). Culturally informed sport psychology practice: Nigeria in perspective. Journal of Clinical Sport Psychology, 5(4), 339.

Ikulayo, P. B., \& Semidara, J. A. (2009). Working with Nigerian athletes. In R. J. Schinke \& S. J. Hanrahan (Ed.), Cultural sport psychology. Champaign, IL: Human Kinetics.

Isogai, H., Brewer, B. W., Cornelius, A. E., Etnier, J., \& Tokunaga, M. (2003). A cross-cultural analysis of goal orientation in American and Japanese physical education students. International Journal of Sport Psychology, 34, 80-93. 
Isogai, H., Brewer, B. W., Cornelius, A. E., Komiya, S., Tokunaga, M., \& Tokushima, S. (2001). Cross-cultural validation of the Social Physique Anxiety Scale. International Journal of Sport Psychology, 32, 76-87.

Jirásek, I. (2015). Religion, spirituality, and sport: From religio athletae toward spiritus athletae. Quest, 67(3), 290-299. http://dx.doi.org/10.1080/00336297.2015.1048373

Jirásek, I. (2010). The forgotten paradigm: Spirituality of games and play. In A. Hardman \& C. Jones (Eds.), Philosophy of sport: International perspectives (pp. 72-83). Newcastle upon Tyne, England: Cambridge Scholars.

Koenig, H. G., McCullough, M. E., \& Larson, D. B. (2001). Handbook of religion and health. New York: Oxford.

Kolt, G. S., Kirkby, R. J., Bar-Eli, M., Blumenstein, B., Chadha, N. K., Liu, J., \& Kerr, G. (1999). A cross-cultural investigation of reasons for participation in gymnastics. International Journal of Sport Psychology, 30, 381-398.

Maranise, A. M. (2013). Superstition and religious ritual: An examination of their effects and utilization in sport. The Sport Psychologist, 27, 83-91.

Mesquita, B., \& Frijda, N. H. (1992). Cultural variations in emotion: A review. Psychological Review, 112, 179-204. http://dx.doi.org/10.1037/0033-2909.112.2.179

Miller, P. S., \& Kerr, G. A. (2002). Conceptualizing excellence: Past, present, and future. Journal of Applied Sport Psychology, 14, 140-153.

Moraes, L. C., \& Salmela, J. H. (2009). Working with Brazilian athletes. In R. J. Schinke \& S. J. Hanrahan (Eds.), Cultural sport psychology. Champaign, IL: Human Kinetics.

Moran, A. P. (1996). The psychology of concentration in sport performers: A cognitive analysis. Hove: Psychology Press.

Ofori, P. K., Tod, D., \& Lavallee, D. (2016). An exploratory investigation of superstitious behaviors, coping, control strategies, and personal control in Ghanaian and British student-athletes. International Journal of Sport and Exercise Psychology, 1-17.

Pannenborg, A. (2012). Big men playing football: Money, politics and foul play in the African game. Leiden: African Studies Centre.

Pannenborg, A. (2008). How to win a football match in Cameroon: An anthropological study of Africa's most popular sport. Leiden: African Studies Centre.

Papaioannou, A. G. (2006). Muslim and Christian students' goal orientations in school, sport, and life. International Journal of Sport and Exercise Psychology, 4, 250-282.

Parker, A., \& Watson, N. J. (2014). Sport and religion: culture, history and ideology. Movement \& Sport Sciences, (4), 71-79.

Parry, J., Watson, N., \& Nesti, M. (2011). Theology, ethics and transcendence in sports. New York, NY: Routledge.

Peres, J. F., Moreira-Almeida, A., Nasello, A. G., \& Koenig, H. G. (2007). Spirituality and resilience in trauma victims. Journal of Religion and Health, 46(3), 343-350.

Plante, T. G. (2008). What do the spiritual and religious traditions offer the practicing psychologist? Pastoral Psychology, 56(4), 429-444.

Plante, T. G. (2007). Integrating spirituality and psychotherapy: Ethical issues and principles to consider. Journal of Clinical Psychology, 63, 891-902.

Plante, T. G., \& Thoresen, C. E. (Eds.) (2007). Spirit, science and health: How the spiritual mind fuels the body. Westport, CT: Praeger/Greenwood.

Ravizza, K. H. (2002). A philosophical construct: A framework for performance enhancement. International Journal of Sport Psychology, 33(1), 4-18.

Reid, H. L. (2009). Olympic sport and its lessons for peace. In K. Georgiadis, \& A. Syrigos (Eds.), Olympic truce: Sport as a platform for peace (pp. 25-35). Athens: The International Olympic Truce Centre.

Roberts, K. A., \& Yamane, D. (2012). Religion in sociological perspective $\left(5^{\text {th }}\right.$ ed.). Thousand Oaks, CA: Pine Forge Press.

Robinson, S. (2007a). Spirituality: A story so far. Sport and spirituality. London: Routledge.

Ryba, T. V., Schinke, R. J., Stambulova, N. B., \& Elbe, A. M. (2017). ISSP position stand: Transnationalism, mobility, and acculturation in and through sport. International Journal of Sport and Exercise Psychology, 1-15. 
Ryba, T. V., Stambulova, N. B., Si, G., \& Schinke, R. (2013). ISSP position stand: Culturally competent research and practice in sport and exercise psychology. International Journal of Sport and Exercise Psychology, 11, 123-142.

Ryba, T. V., \& Wright, H. K. (2010). Sport psychology and the cultural turn: Notes toward cultural praxis. In T. V. Ryba, R. J. Schinke, \& G. Tenenbaum (Eds.), The cultural turn in sport psychology (pp. 1-28). Morgantown, WV: Fitness Information Technology.

Ryba, T. V., \& Wright, H. K. (2005). From mental game to cultural praxis: A cultural studies model's implications for the future of sport psychology. Quest, 57, 192-212.

Sarkar, M., Hill, D. M., \& Parker, A. (2015). Reprint of: Working with religious and spiritual athletes: Ethical considerations for sport psychologists. Psychology of Sport and Exercise, 17, 48-55.

Schack, T. \& Hackfort, D. (2007). Action theory approach to applied sport psychology. In G. Tenenbaum \& R. C. Eklund (Eds.), Handbook of Sport Psychology (3rd ed., pp. 332-351). John Wiley \& Sons.

doi:10.1002/9781118270011.ch15

Schack, T., \& Schack, E. (2017). Anticipation in traditional healing ceremonies - The call from our past. In M. Nadin (Eds.), Anticipation in medicine. New York: Springer.

Schack, T., Whitmarsh, B., Pike, R., \& Redden, C. (2005). Routines. In J. Taylor \& G. Wilson (Eds.), Applying sport psychology: Four perspectives (pp. 137-150). Champaign, IL: Human Kinetics.

Schinke, R. J. (2005). Editorial. Athletic Insight. Retrieved March 2017 from http://www.athleticinsight.com/Vol7Iss3/Editorial.htm

Schinke, R. J., Hanrahan, S. J., \& Catina, P. (2009). Introduction to sport psychology. In R. J. Schinke, \& S. J. Hanrahan (Eds.), Cultural sport psychology (pp. 3-12). Champaign, IL: Human Kinetics.

Schinke, R. J., \& McGannon, K. R. (2015). Cultural sport psychology and intersecting identities: An introduction in the special section. Psychology of Sport and Exercise, 17, 45-47.

Schinke, R. J., \& Moore, Z. E. (2011). Culturally informed sport psychology: Introduction to the special issue. Journal of Clinical Sport Psychology, 5, 283-294. Retrieved from: http://journals.humankinetics.com/icsp

Schinke, R. J., Stambulova, N. B., Si, G., \& Moore, Z. (2017). International society of sport psychology position stand: Athletes' mental health, performance, and development. International Journal of Sport and Exercise Psychology, 118.

Schinke, R. J., Stambulova, N. R., Lidor, R., Papaioannou, A., \& Ryba, T. V. (2015). ISSP position stand: Social missions through sport and exercise psychology. International Journal of Sport and Exercise Psychology, 14(1), 422.

Seligman, M. E. P., \& Csikszentmihalyi, M. (2000). Positive psychology: An introduction. American Psychologist, 55, 5e14. http://dx.doi.org/10.1037//0003-066X.55.1.5.

Si, G., Rethorst, S., \& Willimczik, K. (1995). Causal attribution perception in sports achievement: A cross-cultural study on attributional concepts in Germany and China. Journal of Cross-Cultural Psychology, 26, 537-553.

Stambulova, N., Stephan, Y., \& Jäphag, U. (2007). Athletic retirement: A cross-national comparison of elite French and Swedish athletes. Psychology of Sport and Exercise, 8, 101-118.

Storch, E. A., Kolsky, A. R., Silvestri, S. M., \& Storch, J. B. (2001). Religiosity of elite college athletes. The Sport Psychologist, 15(3), 346-351.

Storch, E. A., Storch, J. B., Kovacs, A. H., Okun, A., \& Welsh, E. (2003). Intrinsic religiosity and substance use in intercollegiate athletes. Journal of Sport and Exercise Psychology, 25, 248-252.

Tyler, B. D., \& Cobbs, J. B. (2015). Rival conceptions of rivalry: why some competitions mean more than others. European Sport Management Quarterly, 15(2), 227-248.

Urry, J. (2000). Mobile sociology. British Journal of Sociology, 51, 185-203.

Velentzas, K., Heinen, T., Tenenbaum, G., \& Schack, T. (2010). Functional mental representation of volleyball routines in German youth female national players. Journal of Applied Sport Psychology, 22, 474-485.

Vernacchia, R. A., McGuire, R. T., Reardon, J. P., \& Templin, D. P. (2000). Psychosocial characteristics of Olympic track and field athletes. International Journal of Sport Psychology, 31(1), 5-23.

Watson, N. J. (2011). Identity in sport: A psychological and theological analysis. In J. Parry., M. N. Nesti, M., \& N. J. Watson (Eds.), Theology, ethics and transcendence in sports (pp.107-148), London, UK: Routledge. 
Watson, N. J., \& Nesti, M. (2005). The role of spirituality in sport psychology consulting: An analysis and integrative review of literature. Journal of Applied Sport Psychology, 17(3), 228-239.

Watson, N. J. \& White, J. (2012). C. S. Lewis at the 2012 London Olympics: Reflections on pride and humility, practical theology, 5, 2, 153-169. http://essential.metapress.com/content/n24361nr7762j38j/fulltext.pdf

Yang, K. (1997). Indigenizing westernized Chinese psychology. In M. H. Bond (Ed.), Working at the interface of culture: Twenty lives in social science. London: Routledge. 